\title{
Field Tests of Performance and Their Relationship to Age and Anthropometric Parameters in Adolescent Handball Players
}

\author{
Mehrez Hammami1,2, Souhail Hermassi ${ }^{*}$, Nawel Gaamouri1,2, Gaith Aloui ${ }^{1}$, \\ Paul Comfort ${ }^{4}$, Roy J. Shephard ${ }^{5}$ and Mohamed Souhaiel Chelly ${ }^{1,2}$
}

${ }^{1}$ Research Unit (UR17JS01) Sport Performance, Health and Society, Higher Institute of Sport and Physical Education of Ksar Saïd, University of "La Manouba", Tunis, Tunisia, ${ }^{2}$ Higher Institute of Sport and Physical Education of Ksar Saïd, University of "La Manouba", Tunis, Tunisia, ${ }^{3}$ Sport Science Program, College of Arts and Sciences, Qatar University, Doha, Qatar, ${ }^{4}$ Directorate of Sport, Exercise and Physiotherapy, University of Salford, Salford, United Kingdom, ${ }^{5}$ Faculty of Kinesiology and Physical Education, University of Toronto, Toronto, ON, Canada

\section{OPEN ACCESS}

Edited by:

Luca Paolo Ardigò,

University of Verona, Italy

Reviewed by:

Iker J. Bautista,

Aitor Mira Physiotherapist Clinic,

Spain

Karsten Krüger,

Leibniz University Hannover, Germany Herbert Wagner,

University of Salzburg, Austria

${ }^{*}$ Correspondence:

Souhail Hermass

shermassi@qu.edu.qa

Specialty section:

This article was submitted to

Exercise Physiology,

a section of the journal

Frontiers in Physiology

Received: 27 December 2018

Accepted: 14 August 2019

Published: 06 September 2019

Citation:

Hammami M, Hermassi S,

Gaamouri N, Aloui G, Comfort P, Shephard RJ and Chelly MS (2019)

Field Tests of Performance and Their

Relationship to Age and Anthropometric Parameters in Adolescent Handball Players.

Front. Physiol. 10:1124.

doi: 10.3389/fphys.2019.01124
Handball performance is influenced by age, anthropometric characteristics, technical skills, tactical understanding, and physical abilities. The aims of this study were (i) to determine differences in anthropometric characteristics and physical performance between adolescent handball players across age categories, and (ii) to determine which anthropometric and maturity variables have the greatest relative importance in fitness for this sport. Seventy-nine male handball players drawn from a team in the elite Tunisian Handball league [U18 ( $n=10) ; \mathrm{U} 17(n=12) ; \mathrm{U16}(n=17) ; \mathrm{U15}(n=18) ;$ and U14 $(n=22)]$ volunteered for the investigation. Assessments included sprint performances; change in direction tests (T-half test and Illinois modified test); jumping tests (squat jump; counter movement jump; countermovement jump with aimed arms; five-jump test); medicine ball throwing; handgrip force; back extensor force and selected anthropometric measurements. The individual's age category affected all measurements, with U17 and U18 players showing larger body measurements and significantly better absolute results on all physical tests than U14, U15 and U16 contestants. Scores for the majority of physical performance tests were closely inter-correlated. We conclude that U17 and U18 players show significantly better absolute results than the younger players on all physical tests. Multiple linear regressions, using block-wise entry, indicate that age is the strongest predictor of jump and sprint performances. Several anthropometric characteristics, including body mass, standing height and lower limb length were closely correlated with performance test scores, but after allowing for age only body mass added to the prediction of jumping ability.

Keywords: sitting height, handgrip force, back extensor force, anthropometric characteristics, ball games

\section{INTRODUCTION}

Handball performance is influenced not only by anthropometric characteristics, but also by technical skills, tactical understanding, and physical abilities that develop with a player's age (Chelly et al., 2010; Kruger et al., 2014; Schwesig et al., 2016). Contestants must undertake repeated periods of high intensity activity, sprinting, jumping, changing direction rapidly, making physical contacts, 
and throwing they pass the ball, block opponents, and attempt to establish an optimal position for the throwing player, alternating with rapid recovery during periods of low intensity activity (Michalsik et al., 2013; Wagner et al., 2014, 2017, 2018, 2019; Michalsik et al., 2015; Hermassi et al., 2018a,b). The strength and power of both upper and lower limb muscles are important determinants of sprinting, jumping, throwing (Hermassi et al., 2017s) and changing direction rapidly (Hermassi et al., 2017b). It has thus been suggested that field assessments of handball players should include a broad range of measures of sprinting, jumping, ability to change direction and maximal strength (Matthys et al., 2013; Massuca et al., 2015; Haugen et al., 2016; Ortega-Becerra et al., 2018; Wagner et al., 2019). However, there may be considerable redundancy in typical assessments, since performance test scores are often quite closely correlated both with one another and with anthropometric data.

The only relevant previous study of adolescent players (Ortega-Becerra et al., 2018) focused upon a number of physical characteristics affecting throwing performance in 44 male players ranging from elite professionals to under-16 contestants. The present investigation examined widely used field measures (sprint times, change in direction tests, vertical jumping and upper and lower limbs strength) in adolescent handball players across various age categories, looking at the extent of correlations between individual test measures, and examining their relationships to age category and selected anthropometric characteristics (standing and sitting height, lower limb length and percentage body fat). Multiple linear regression analyses (MLR) examined how far measures of maturity and anthropometric characteristics added to the description of ability provided by age alone. Our initial hypotheses were (i) that anthropometric characteristics and physical performance would develop significantly over the age categories studied, and (ii) that a player's anthropometric characteristics would add to an age-related prediction of physical performance.

\section{MATERIALS AND METHODS}

\section{Participants}

The study was reviewed and approved by the Institute's Committee on Research for the Medical Sciences (Manouba University Ethics Committee), in accordance with current national laws and regulations and the Helsinki Declaration. Informed consent was gained from all participants and their parents or guardians after a verbal and a written explanation of the experimental protocol and its potential risks and benefits. Participants were assured that they could withdraw from the trial without penalty at any time.

Seventy-nine male U18 handball players with at least of 5 years playing experience, drawn from a team belonging to the first Tunisian Handball league volunteered to participate in the investigation; details of training experience, playing positions, handedness and maturity status are summarized in Table 2. All were in good health and had passed a medical examination provided by the team physician before commencing the study. Their maturity status was calculated as a maturity offset (Mirwald et al., 2002):

Maturity Offset $=-9.236+0.000278$ leg length $\times$ sitting height -0.001663 age $\times$ leg length +0.007216 age $\times$ sitting height +0.02292 weight $\times$ height (years)

Players were instructed to avoid any strenuous exercise on the day before testing, and no additional training was conducted on the 2 test days. The training routine comprised repeated $\sim 90$ min training sessions (8 per week for U18; 6 for U17 and U16; 5 per week for U15 and U14), together with a competitive game played on the weekend. Training consisted mainly of tactical skill development ( $60 \%$ of session time) and strength and conditioning routines ( $40 \%$ of session time).

\section{Experimental Design}

We examined differences in anthropometric characteristics and physical performance of adolescent handball players across age categories, looked at test redundancy in terms of inter-correlations between the various performance measures, and finally examined the influence of age and anthropometric characteristics upon performance using both univariate and multi-variate regression equations.

When testing was undertaken, all players had been training for 5 months, and they were already 4 months into the competitive season (January 2017). Two weeks before definitive measurements, two test familiarization sessions were completed. The definitive protocol included anthropometric measures and assessments of sprint performance over 5-, 10-, 20-, and 30-m distances; change in direction tests [T-half test (T-half) and Illinois modified test (Illinois-MT)]; jumping tests [squat jump (SJ); counter movement jump (CMJ); countermovement jump with aimed arms (CMJA); five-jump test (5JT)]; a medicine ball throw; and determinations of handgrip force (HG) and back extensor strength. All test measurements were made at the same time of day, and under the same experimental conditions. Participants maintained their normal intake of food and fluids, but they abstained from physical exercise for 1 day, drank no caffeine-containing beverages for $4 \mathrm{~h}$, and ate no food for $2 \mathrm{~h}$ before testing. A $15 \mathrm{~min}$ active warm-up comprising running, jumping, sprinting for short distances $(10$ and $15 \mathrm{~m})$ and mobility exercises, as well as sport-specific drills with or without the ball) preceded each day's testing, and verbal encouragement ensured maximal effort throughout.

\section{Testing Schedule}

Definitive tests were performed in a fixed order over 3-days. On the first day, anthropometric measurements were followed by vertical jump tests (SJ; CMJ; and CMJA). The second day was devoted to medicine ball testing, Illinois-MT, Back Extensor Strength measurements and 5JT. On the third day, $30 \mathrm{~m}$ sprint performance was evaluated, followed by the handgrip test and the T-half test. 


\section{Anthropometry}

Anthropometric measurements included: standing and sitting heights (Holtain stadiometer, Crosswell, Crymych, Pembrokeshire, United Kingdom, accuracy of $1 \mathrm{~mm}$ ) and body mass (Tanita BF683W scale, Munich, Germany, accuracy of $0.1 \mathrm{~kg}$ ). The overall percentage of body fat was estimated from the biceps, triceps, subscapular, and suprailiac skinfolds, using the equations of Durnin and Womersley (1974) for adolescent males aged $16.0-19.9$ years:

$\%$ Body fat $=[4.95 /($ Density -4.5$)] \times 100$

Where: Density $=1.1533-0.0643$ (Log sum of 4 skinfolds) for participants $<17$ years old, and

Density $=1.162-0.063$ (Log sum of 4 skinfolds) for participants 17 - and 19 years old

\section{Vertical Jumping}

Jump height was assessed by the same investigator, using an infrared photocell mat connected to a digital computer (Optojump System, Microgate SARL, Bolzano, Italy). The optical acquisition system measured contact and flight times during a jump with a precision of $1 / 1000 \mathrm{~s}$ and calculated the jump height from this data. One minute of rest was allowed between the three trials of each test, the highest jump being used in subsequent analyses. Participants were instructed to land with the legs fully extended and then to flex the limbs on landing, to avoid artificially inflating flight-time. Participants began the SJ at a knee angle of 90 degrees, and avoiding any downward movement, they performed a vertical jump by pushing upward, keeping their legs straight throughout. The CMJ began from an upright position, with participants making a rapid downward movement to a knee angle of approximately $90^{\circ}$, arms akimbo and simultaneously beginning to push-off, after being instructed to jump as fast and high as possible. The hands were freely used during the CMJA.

\section{Medicine Ball Throw}

Medicine ball throws were performed using $21.5 \mathrm{~cm}$ diameter 1 and $3 \mathrm{~kg}$ rubber medicine balls (Tigar, Pirot, Serbia). All subjects began with a familiarization session. A brief description of the optimal technique was given, suggesting a release angle to achieve a maximum distance of throw (Gillespie and Keenum, 1987). The medicine ball was lightly covered with chalk powder (magnesium carbonate) to absorb sweat and ensure a firm grip on the ball. The talc also marked the floor where the ball landed, allowing a precise measurement of the throwing distance. The sitting player grasped the medicine ball with both hands, and on the given signal forcefully pushed the ball from the chest. The score was measured from the front of the sitting line to the place where the ball landed.

\section{Modified Change in Direction Illinois Test}

Modified Illinois test (Illinois-MT) outcomes were recorded using an electronic timing system (Microgate SARL, Bolzano, Italy). Two pairs of tripod-mounted timing sensors were set $1 \mathrm{~m}$ above the floor and facing each other $3 \mathrm{~m}$ apart on either side of the starting and finishing lines. The front foot was positioned on a line $0.20 \mathrm{~m}$ in front of the photocell beam. The change in direction area for the Illinois-MT was set-up with four cones.
On command, the player sprinted $5 \mathrm{~m}$ from a standing position, turns and came back to the starting line; then swerved in and out of the four markers, completing two $5 \mathrm{~m}$ sprints to finish the course (Hachana et al., 2014). Participants were told to complete the test as quickly as possible, but no advice is given on technique. They were also instructed not to cut over the markers, but to run around them. If they failed to do this, the trial was stopped and re-attempted after a standard recovery period.

\section{Back Extensor Strength}

Maximal isometric back extensor strength was measured in kilograms, using back and leg dynamometers (Takei, Tokyo, Japan) as previously described (Hannibal et al., 2006). Participants stood on the dynamometer foot stand with their feet one shoulder-width apart and gripped the handle bar positioned across the thighs. The chain-length of the dynamometer was adjusted so that initially the legs were fully extended and the back was flexed at a $30^{\circ}$ angle, positioning the bar at the level of the patella. Participants then stood upright without bending their knees and lifted the dynamometer chain, pulling upward as strongly as possible. Three trials were completed, and the highest score was recorded. A 30-s rest interval was allowed between each trial.

\section{Five-Jump Test (5JT)}

The 5JT began from an upright standing position, with both feet flat on the ground. Participants tried to cover as much distance as possible with five forward jumps, alternating left- and rightleg ground contacts. The distance covered was measured to the nearest $1 \mathrm{~cm}$ using a tape measure (Meylan and Malatesta, 2009).

\section{0 m Sprint Performance}

Times over distances of 5-, 10-, 20-, and $30 \mathrm{~m}$ were recorded using a series of paired photocells (Microgate, Bolzano, Italy). Participants started from a standing position, with the front foot $0.2 \mathrm{~m}$ from the first photocell beam. Three trials were separated by 6-8 min of recovery, with the best result for each distance being noted.

\section{Handgrip Force}

The subject held the hand dynamometer (Takei, Tokyo, Japan) with the arm at right angles and the elbow by the side of the body. The handle of the dynamometer was adjusted so that the base rested on first metacarpal and the handle rested on the middle of the four fingers. The dynamometer was squeezed maximally, and the contraction was maintained for $5 \mathrm{~s}$. No ancillary body movements were allowed. Two trials were made with each hand, with $1 \mathrm{~min}$ of rest between trials. The highest readings were used in subsequent analyses.

\section{Modified Change in Direction $t$-Test}

The $t$-test was used to determine speed with directional changes such as forward sprinting, left and right shuffling, and back-pedaling. Subjects began the test with both feet behind starting line A (Sassi et al., 2009). Participants sprinted forward to cone $\mathrm{B}$ and touched the base of it with their right hand. Facing forward and without crossing feet, they then shuffled to the left to cone $\mathrm{C}$ and touched its base with the left hand. They next shuffled 
to the right to cone $\mathrm{D}$, touching its base with the right hand. They then shuffled back to cone B, touching its base. Finally, they ran back as quickly as possible to line A. If they crossed one foot in front of the other, failed to touch the base of a cone, and/or failed to face forward throughout, they had to repeat the test. Two trials were conducted and the shortest time was recorded.

\section{Statistical Analyses}

All statistical analyses were performed using SPSS version 22.0 for Windows (SPSS Inc., Chicago, IL, United States). The reliabilities of all dependent variables were assessed by calculating two-way mixed intra-class correlation coefficients (Vincent, 1995). Descriptive statistics [mean and standard deviation (SD)] were ascertained for all variables. Comparisons between age groups were performed using a series of one-way analyses of variance. If a significant $F$ value was observed, Tukey's post hoc procedure was applied to locate pair-wise differences. Pearson's product moment correlation was calculated and used to determine relationships between all tests.

Multiple linear regressions (MLR) were calculated using a hierarchical block-wise entry method. Firstly, we tested how much variance our measure of maturity contributed to a simple age prediction of each variable. Then we analyzed how much each of a sequence of anthropometric variables supplemented this description, with the order of entry of predictors into the equation selected on the basis of univariate correlations with the performance variable in question and knowledge of past work. The number of physical performance variables was reduced for these analyses. Individual data for a characteristic such as sprinting were arbitrarily weighted, based on their correlations with anthropometric data (Table 5). Performance measures were then expressed as a percentage of the corresponding group mean (performance for individual - mean performance) $\times 100) /$ mean performance, as shown in the following examples:

Composite Sprint score $=(\mathrm{aS} 5 \mathrm{~m} \%+\mathrm{bS} 10 \mathrm{~m} \%+\mathrm{cS} 20 \mathrm{~m} \%+$ $\mathrm{dS} 30 \mathrm{~m} \%)$.

Composite change in direction score $=($ aT-half $\%+$ bIllinoisMT\%).

Composite jump score $=($ aSJ $\%+$ bCMJ $\%+c C M J A \%+d 5 J T \%)$

Composite strength score $=($ aMedicine Ball $\%+$ bHandgrip right $\%+$ cHandgrip left $\%+$ dBack Extensor Strength\%).

Normality of all data sets was checked using the Kolmogorov-Smirnov test. Multicollinearity was estimated by a variance inflation factor (VIF), with a VIF $>10$ indicating excessive multicollinearity. Levene's test checked the homogeneity of variance, and scatter plots tested the linearity assumption.

\section{RESULTS}

\section{Preliminary Analysis of the Data}

Multicollinearity was tested, and height was excluded from the regression models because its VIF was $>10$. Levene's test showed equal variance across samples, and the oval shape of scatter plots test showed linearity of the data. All performance measurements
TABLE 1 | Intra-class correlation coefficients and coefficients of variation for measures of physical performance.

\begin{tabular}{llcr}
\hline Performance test & ICC & 95\%Cl of ICC & CV \\
\hline $5 \mathrm{~m}$ & 0.847 & $0.760-0.902$ & 4.8 \\
$10 \mathrm{~m}$ & 0.983 & $0.973-0.989$ & 5.2 \\
$20 \mathrm{~m}$ & 0.996 & $0.993-0.997$ & 6.8 \\
$30 \mathrm{~m}$ & 0.967 & $0.948-0.979$ & 7.3 \\
T-half & 0.987 & $0.980-0.992$ & 4.3 \\
Illinois-MT & 0.952 & $0.926-0.970$ & 2.7 \\
SJ & 0.921 & $0.876-0.949$ & 15.5 \\
CMJ & 0.984 & $0.975-0.990$ & 14.8 \\
CMJA & 0.926 & $0.884-0.953$ & 13.9 \\
5JT & 0.990 & $0.984-0.993$ & 17.1 \\
Medicine ball throw & 0.947 & $0.917-0.966$ & 20 \\
Handgrip force right & 0.975 & $0.933-0.973$ & 17.1 \\
Hand grip force left & 0.902 & $0.846-0.937$ & 16 \\
Back extensor strength & 0.967 & $0.948-0.979$ & 12.3
\end{tabular}

5JT, five-jump test; Cl, confidence intervals; CMJ, counter-movement jump; CMJA, counter-movement jump aimed arms; CV, coefficient of variation; ICC, intra-class correlation coefficient; MT, modified test; SJ, squat jump.

reached an acceptable level of reliability (Table $1 ; r>0.80)$. All variables showed a normal distribution.

\section{Age Effects}

There were significant main effects of age for all measurements of both physical characteristics (Table 2) and performance test scores (Table 3) and the majority of physical performance measures showed moderate to very large associations (Table 4). Chronological age had a consistently larger univariate effect on all variables than the age at peak height velocity (Table 5). The U17 and U18 age categories showed significantly larger anthropometric dimensions and larger absolute values for all physical test scores than the U14, U15, and U16 groups. The U16, U17 and U18 groups also performed significantly better than the U14 and U15 for all sprint COD times (Table 3). A consistent age trend was also seen in vertical and five-jump tests; although U17 and U18 players did not differ statistically from each other, significant inter-group differences were found for U 14, U 15, and U 16 players (Table 3 ).

\section{Test Redundancy}

The correlation matrix showed that sprint-times over distances of 5-30 m were closely correlated with each other as were the standing jump, counter-movement jump score with and without use of the arms.

\section{Relationships Between Anthropometric Characteristics and Physical Performance}

The majority of physical performance measures showed moderate to very large univariate associations with most anthropometric characteristics (Table 5), correlations being particularly strong for lower limb length, body mass, and standing height. However, back extensor strength did not 
TABLE 2 | Comparison of physical characteristics across age categories.

\begin{tabular}{|c|c|c|c|c|c|}
\hline Player category & U14 (n= 22) & U15 $(n=18)$ & U16 $(n=17)$ & U17 $(n=12)$ & U18 $(n=10)$ \\
\hline Age (years) & $13.8 \pm 0.3 a^{* * *} b^{* * *} c^{* * *} d^{* * *}$ & $14.7 \pm 0.3 a^{* * *} b^{* * *} c^{* * *}$ & $15.8 \pm 0.3 a^{* * *} b^{* * *}$ & $16.6 \pm 0.3 a^{* * *}$ & $17.7 \pm 0.3$ \\
\hline APHV (years) & $14.1 \pm 0.4 \mathrm{a}^{* * *} \mathrm{~b}^{* * *} \mathrm{c}^{* * *}$ & $14.1 \pm 0.3 \mathrm{a}^{* * *} \mathrm{~b}^{* * *} \mathrm{c}^{* * *}$ & $14.7 \pm 0.34$ & $15.0 \pm 0.5$ & $15.0 \pm 0.4$ \\
\hline Body mass (kg) & $68.2 \pm 4.4 \mathrm{a}^{* * *} \mathrm{~b}^{*}$ & $68.7 \pm 3.8 a^{* * *}$ & $69.9 \pm 5.8 \mathrm{a}^{* * *}$ & $74.0 \pm 8 \mathrm{a}^{* * *}$ & $86.3 \pm 5.9$ \\
\hline Height (cm) & $167.9 \pm 5.9 a^{* * *} b^{* * *} c^{* * *} d^{* * *}$ & $175.7 \pm 5.3 a^{* *}$ & $179.3 \pm 2.8$ & $180.1 \pm 3.3$ & $182.5 \pm 2.4$ \\
\hline Sitting height $(\mathrm{cm})$ & $79.1 \pm 3.4 a^{* * *} b^{*} c^{*} d^{*}$ & $82.0 \pm 1.9 \mathrm{a}^{* *}$ & $81.8 \pm 2.2 \mathrm{a}^{* *}$ & $82.2 \pm 3.5 \mathrm{a}^{* *}$ & $86.2 \pm 2.2$ \\
\hline Lower limb length (cm) & $88.8 \pm 4.6 a^{* * *} b^{* * *} c^{* * *} d^{* * *}$ & $93.7 \pm 4.2 b^{*} c^{*}$ & $97.4 \pm 1.8$ & $97.9 \pm 2.2$ & $96.3 \pm 1.4$ \\
\hline Body fat $\%$ & $23.1 \pm 7.2$ & $21.6 \pm 7.8$ & $19.3 \pm 6.2$ & $21 \pm 5.3$ & $17.7 \pm 7.6$ \\
\hline Training experience (years) & $5.4 \pm 0.5$ & $5.7 \pm 0.5$ & $6 \pm 0.9$ & $6.5 \pm 1$ & $7.8 \pm 0.8$ \\
\hline Right handed & 16 & 13 & 11 & 10 & 8 \\
\hline Left handed & 6 & 5 & 6 & 2 & 2 \\
\hline Back players & 8 & 6 & 6 & 3 & 3 \\
\hline Wing players & 7 & 5 & 5 & 4 & 3 \\
\hline Pivots players & 4 & 4 & 3 & 3 & 2 \\
\hline Goal-keepers & 3 & 3 & 3 & 2 & 2 \\
\hline
\end{tabular}

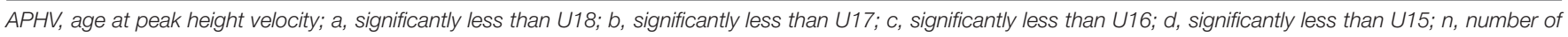
subjects; $U$, under. ${ }^{*} p<0.05 ;{ }^{* *} p<0.01 ;{ }^{* *} p<0.001$.

influence sprinting or COD performance. Further, age, height, and lower limb length were significantly correlated with the results of all physical tests (Table 5). Body mass was also significantly correlated with the majority of physical performance measures except CMJ, CMJA, and 5JT. In contrast, body fat percentage (over the range of body fat values found in these players) was not correlated with any of the physical performance scores (Table 5).

\section{Multiple Regression Analyses}

Some $59.3 \%$ of the variance in composite sprint score was attributable to age. After inclusion of this variable, no other potential terms in the prediction equation achieved statistical significance (Table 6). The equation for prediction of sprinting performance was thus:

Composite sprint score $(\%)=-3.04$ Age $($ year $)+46.6$

In terms of the composite jump score, $48.3 \%$ of the variance was explained by calendar age. Addition of the maturity variable (APHV) did not significantly change the prediction (Table 7). Body mass added a significant $4 \%$ to the description of variance, but after introduction of this variable, neither leg length nor body fat content added significantly to the regression. The jump score could thus be predicted using the equation:

Composite jump score $(\%)=8.43$ Age (year) -0.48 Body mass (kg) -94.6

For the composite change in direction score, age, age at peak height velocity and leg length all contributed to the description of variance (Table 8), with the final equation contributing $59.3 \%$ of the variance in performance:

Composite change in direction score $(\%)=-1.82$ Age (year) +1.66 APHV (year) - 1.36 Lower limb length $(\mathrm{cm})+16.8$
Fort the composite strength scores, $63.8 \%$ of the variance was described by age, with none of the other variables contributing to this description (Table 9). Thus, Composite strength score $(\%)=8.23$ Age $($ year $)-126.4$

\section{DISCUSSION}

Aspects of the present findings that merit specific comment include the issue of test redundancy, the impacts of age and maturity upon performance in handball, correlations of performance with anthropometric characteristics, the influence of playing position, and finally some strengths and limitations in the research to date.

\section{Test Redundancy}

The close correlation observed between many of the performance measures used in this study highlights a substantial redundancy in the tests that are presently used in assessments of performance for team sports; inter-correlations are particularly close for the four sprint times and for the several measures of jumping performance (Table 4). Others, also, have commented on such inter-relationships and test redundancies (Chaouachi et al., 2009; Chelly et al., 2010; Schwesig et al., 2017; Ortega-Becerra et al., 2018). There is a need to use techniques such as factor analysis to discern underlying structures and measurements or measurement combinations that are aligned with specific components of actual game performance. This would simplify the task both of measuring laboratories and those practitioners who must interpret the resulting data.

\section{Age Effects}

Age is an important variable for handball players (Lidor et al., 2005). Our age comparisons were admittedly cross-sectional in nature, but selection pressures were similar for each age category, and effects from social changes and secular trends to an increase 
TABLE 3 | Comparison of athletic performance of study participants across age categories.

\begin{tabular}{|c|c|c|c|c|c|}
\hline Age category & U14 (n = 22) & U15 $(n=18)$ & U16 $(n=17)$ & U17 $(n=12)$ & U18 $(n=10)$ \\
\hline \multicolumn{6}{|l|}{ Sprint times } \\
\hline $5 \mathrm{~m}(\mathrm{~s})$ & $1.22 \pm 0.05 a^{* * *} b^{* * *} c^{* * *}$ & $1.21 \pm 0.06 a^{* *} b^{* *} c^{* *}$ & $1.15 \pm 0.04$ & $1.14 \pm 0.02$ & $1.14 \pm 0.05$ \\
\hline $10 \mathrm{~m}(\mathrm{~s})$ & $2.10 \pm 0.07 \mathrm{a}^{* * *} \mathrm{~b}^{* * *} \mathrm{c}^{* * *}$ & $2.08 \pm 0.09 a^{* * *} b^{* * *} c^{* * *}$ & $1.91 \pm 0.05$ & $1.95 \pm 0.05$ & $1.91 \pm 0.05$ \\
\hline $20 \mathrm{~m}(\mathrm{~s})$ & $3.68 \pm 0.12 a^{* * *} b^{* * *} c^{* * *}$ & $3.73 \pm 0.19 a^{* * *} b^{* * *} c^{* * *}$ & $3.30 \pm 0.05$ & $3.32 \pm 0.05$ & $3.34 \pm 0.21$ \\
\hline $30 \mathrm{~m}(\mathrm{~s})$ & $5.28 \pm 0.19 a^{* * *} b^{* * *} c^{* * *} d^{*}$ & $5.03 \pm 0.41 a^{* * *} b^{* * *} c^{* * *}$ & $4.68 \pm 0.12$ & $4.66 \pm 0.08$ & $4.58 \pm 0.15$ \\
\hline \multicolumn{6}{|c|}{ Times for change in direction tests } \\
\hline T-half (s) & $7.33 \pm 0.27 \mathrm{a}^{* * *} \mathrm{c}^{* *}$ & $7.16 \pm 0.39 a^{* *}$ & $7.01 \pm 0.16$ & $7.10 \pm 0.16 a^{*}$ & $6.78 \pm 0.13$ \\
\hline Illinois-MT (s) & $13.41 \pm 0.25 a^{* * *} b^{* * *} c^{* * *}$ & $13.21 \pm 0.22 a^{* * *} b^{* * *} c^{* *}$ & $12.93 \pm 0.26 a^{* *}$ & $12.84 \pm 0.16$ & $12.60 \pm 0.17$ \\
\hline \multicolumn{6}{|l|}{ Vertical jump heights } \\
\hline SJ $(\mathrm{cm})$ & $25.7 \pm 1.7 a^{* * *} b^{* * *}$ & $26.1 \pm 3.6 a^{* * *} b^{* *}$ & $28.2 \pm 4.8 a^{* *}$ & $30.7 \pm 4.5$ & $33.5 \pm 2.0$ \\
\hline $\mathrm{CMJ}(\mathrm{cm})$ & $27.8 \pm 2.2 a^{* * *} b^{* *}$ & $27.8 \pm 3.5 a^{* * *} b^{*}$ & $30.1 \pm 5.1 \mathrm{a}^{* *}$ & $32.7 \pm 4.2$ & $35.2 \pm 2.7$ \\
\hline $\mathrm{CMJA}(\mathrm{cm})$ & $31.3 \pm 1.5 a^{* * *} b^{* *}$ & $32.1 \pm 3.5 a^{* * *} b^{*}$ & $33.9 \pm 5.3 \mathrm{a}^{*}$ & $36.9 \pm 5.9$ & $39.0 \pm 2.5$ \\
\hline \multicolumn{6}{|l|}{ Horizontal jump } \\
\hline $5 \mathrm{JT}(\mathrm{m})$ & $8.1 \pm 0.4 a^{* * *} b^{* * *} c^{* * *}$ & $8.4 \pm 0.7 a^{*} b^{* * *} c^{* * *}$ & $10.5 \pm 0.7$ & $10.5 \pm 0.6$ & $10.0 \pm 3$ \\
\hline \multicolumn{6}{|l|}{ Strength } \\
\hline Medicine Ball Throw (m) & $3.3 \pm 0.3 a^{* * *} b^{* * *} c^{* * *} d^{* *}$ & $3.7 \pm 0.2 a^{* * *} b^{* * *} c^{* * *}$ & $4.9 \pm 0.4$ & $5.2 \pm 0.3$ & $5.0 \pm 0.4$ \\
\hline Hand grip force right (N) & $356 \pm 23 a^{* * *} b^{* * *} c^{* *}$ & $386 \pm 25 a^{* * *} b^{* *}$ & $416 \pm 68 a^{* * *}$ & $463 \pm 88$ & $504 \pm 32$ \\
\hline Hand grip force left ( $N$ ) & $339 \pm 18 a^{* * *} b^{* * *} c^{* *}$ & $370 \pm 30 a^{* * *} b^{* *}$ & $389 \pm 62 a^{* * *}$ & $436 \pm 70$ & $467 \pm 40$ \\
\hline Back extensor force (N) & $1154 \pm 74 a^{* *} b^{* *}$ & $1241 \pm 84$ & $1174 \pm 180 a^{*} b^{*}$ & $1342 \pm 217$ & $1340 \pm 86$ \\
\hline
\end{tabular}

5JT, five jump test; a, significantly different from U18; $b$, significantly different from U17; c, significantly different from U16; CMJ, counter movement jump; CMJA, counter movement jump aimed arms; $d$, significantly different from U15; MT, modified test; $n$, number; SJ, squat jump; U, under. ${ }^{*} p<0.05 ;{ }^{* *} p<0.01 ;{ }^{* * *} p<0.001$ 


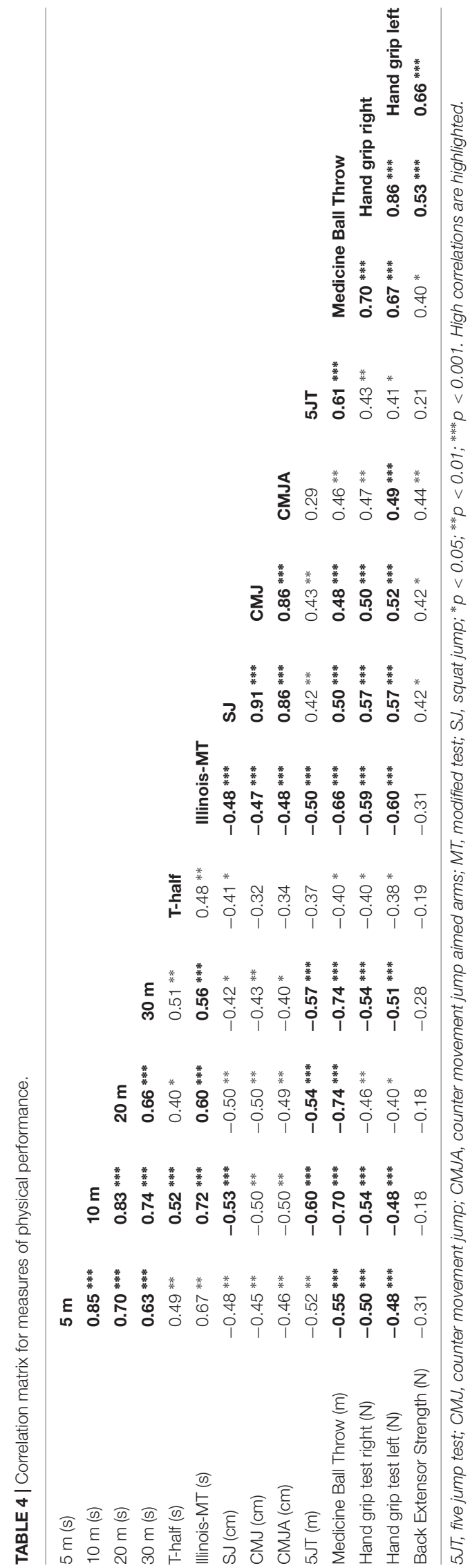

of standing height at any given age are unlikely to have had a major influence over the brief 5-year interval considered here.

There are marked differences in both anthropometric characteristics (Table 2) and physical performance (Table 3) between age categories, and a large part of the total variance in performance variables is described by calendar age (Tables 6-9). This reflects not only the impact of physical growth, but also the accumulation of training, technique and playing experience (Helsen et al., 1998; Salinero et al., 2014). Moreover, in the Tunisian teams, the number and content of training sessions differed between age categories, with 8 (90-min) sessions per week for U18, and 6 training sessions for U17 and U16, but only 5 sessions per week for U15 and U14. Further, the isometric strength training session was reduced for the U 14 category, with loads between 40 to $60 \%$ 1-RM, whereas for U18 the strength training involved loads varying from 40 to $120 \%$ of $1 \mathrm{RM}$ (eccentric contraction). Finally, differences in the percentage of body fat between age categories might have influenced physical performance, since U14 players tended to have a higher percentage of body fat than the other age categories (Table 2).

Inter-individual differences of calendar and biological ages within a given playing category create a relative age effect (Gutierrez Diaz Del Campo, 2010; Prieto-Ayuso et al., 2015), first seen around 12 years of age (Helsen et al., 1998; GómezLópez et al., 2017) and diminishing in the late teens. Those born early after the cut-off date for a given age category have an advantage both in selection and in subsequent performance (Musch and Grondin, 2001; Sherar et al., 2007; Schorer et al., 2009). Consequently, they receive more attention, better training facilities, and more training time (Helsen et al., 2005). In contrast, athletes who are born in the last months of a given age category are often not selected for teams and tend to abandon their sport (Barnsley and Thompson, 1988; Helsen et al., 1998; Delorme et al., 2011).

\section{Maturity Effects}

In addition to overall age differences, there are substantial hormonally based inter-individual differences in growth and maturation during adolescence (Roemmich and Rogol, 1995; Pearson et al., 2006) and one would expect these differences to influence physical performance (Tanner, 1962; Baxter-Jones, 1995). Maturation also results in an upward movement of the center of mass as the legs lengthen (Aouadi et al., 2012), influencing explosive actions such as sprinting or jumping. Vint and Hinrichs (1996) reported that the maximum height reached during a jump was a product of the height of the center of mass and the position of the body relative to the center of mass at the apex of flight.

However, with the exception of the ability to change direction rapidly (Table 8), multiple regression analyses of the present data set showed no significant contribution of age at peak height velocity, once allowance had been made for calendar age. One factor may have been that many of the players had passed the age of rapid adolescent growth. Morphological characteristics have tended to plateau by the age of 16 to 17 years, at least in European children (Van Praagh and Dore, 2002). 


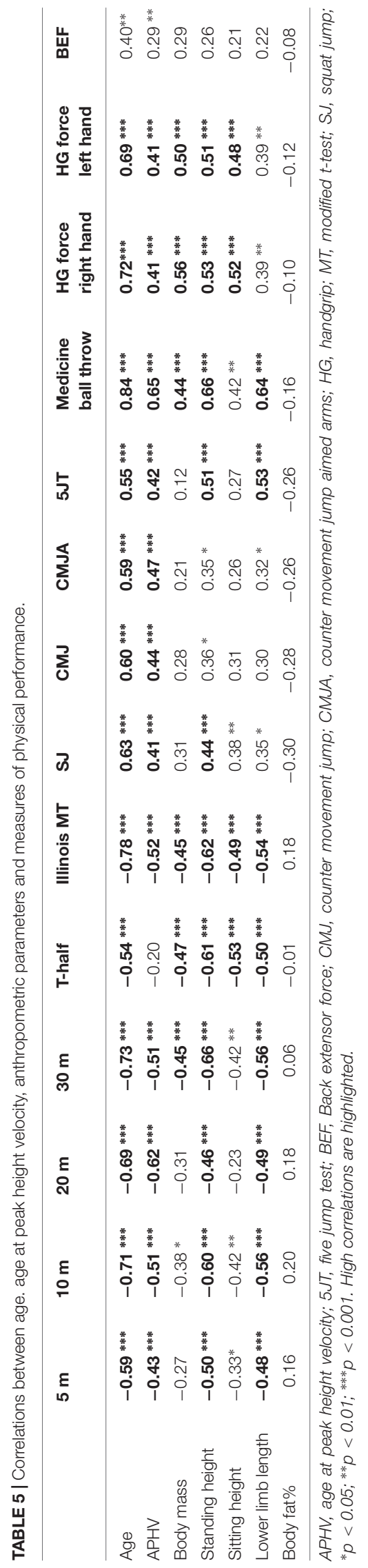

\section{Influence of Anthropometric Factors}

Several authors have discussed the importance of anthropometric variables to the performance of adult handball players (Lidor et al., 2005; Mohamed et al., 2009; Ziv and Lidor, 2009). However, research on adolescent players is limited. Using a stepwise multiple regression analysis, Visnapuu and Jurimae (2007) found that sitting height was associated with scores on basic motor tests fin the 14- to 15-yr.-old group (16.5-52.4\%; $R 2 \times 100)$ and with specific motor skills in 12 - to 13 -yr.-olds and 14 - to 15 -yr.-olds $(13.4-41.6 \%$; $R 2 \times 100)$. Chamari et al. (2008) previously noted that stride length and sprint performance were proportional to leg length. Aouadi et al. (2012) also reported significant relationships between stature, lower limb length, ratio of lower limb length/stature and sitting height/stature to the jump performance of volleyball players, and Kruger et al. (2014) demonstrated a close relationship between anthropometric data, sprinting, jumping, anaerobic and endurance performance.

Lucia et al. (2002) and Fowkes Godek et al. (2004) underlined the negative effects of excessive fat mass, although the International Handball Federation showed a trend toward the selection of heavier players among the best teams, presumably, the additional mass is here muscle rather than fat particularly in wing players (International Handball Federation, 2014). Handgrip strength is also important for catching and throwing the ball (Nag et al., 2003), and our results showed significant inter-group differences in handgrip performance.

Some studies have demonstrated that body composition influences actual game performance. Handgrip strength gives greater control of the ball, and a higher arm-span allows occupation of greater space in defensive and offensive actions (Fernández et al., 2004). Granados et al. (2007) also demonstrated that a greater fat-free mass was associated with a better performance, because of the increase in the muscular power and strength.

Our univariate data showed substantial correlations between several anthropometric parameters and physical performance, particularly standing height, lower limb length and body mass (Table 5), although the percentage of body fat percentage was not related to any performance measures except vertical and horizontal jumping. Body mass was significantly correlated with the score on all performance tests except vertical and horizontal jumping and 5 and $20 \mathrm{~m}$ sprint times. The lack of significant correlation with body mass for these items was surprising. This may possibly reflect differences in familiarity with the CMJA and 5JT. Coordination between the upper and lower limbs is vital to performance of these tests over the age groups studied, with poorer coordination in the younger and less experienced age categories. Further, in multivariate analyses where allowance was made for calendar age, the only statistically significant anthropometric variable was the influence of body mass on ability to change direction (Table 8).

\section{Playing Position}

We did not have a sufficient number of players in any given age category to allow an analysis of our data by playing position. However, technical and physical on-court demands certainly vary 
TABLE 6 | Multiple regression analyses for composite jump scores.

\begin{tabular}{|c|c|c|c|c|c|}
\hline Model & $\mathbf{R}$ & R square & $\begin{array}{l}\text { Adjusted R } \\
\text { square }\end{array}$ & $\begin{array}{l}\text { SE of the } \\
\text { estimate }\end{array}$ & $\begin{array}{l}\text { Sig. } \\
\text { F change }\end{array}$ \\
\hline Model 1: Age & 0.700 & 0.490 & 0.483 & 9.262 & $<0.001$ \\
\hline Model 2: Age + APHV & 0.701 & 0.491 & 0.477 & 9.314 & 0.718 \\
\hline Model 3: Age + body mass & 0.739 & 0.546 & 0.528 & 8.854 & 0.003 \\
\hline Model 4: Age + body mass + LLL & 0.739 & 0.546 & 0.522 & 8.913 & 0.915 \\
\hline Model 5: Age + body mass + body fat & 0.743 & 0.553 & 0.535 & 8.790 & 0.204 \\
\hline
\end{tabular}

LLL: lower limb length.

TABLE 7 | Multiple regression analyses for composite sprint scores.

\begin{tabular}{|c|c|c|c|c|c|}
\hline Model & $\mathbf{R}$ & $\mathbf{R}$ square & $\begin{array}{l}\text { Adjusted R } \\
\text { square }\end{array}$ & $\begin{array}{l}\text { SE of the } \\
\text { estimate }\end{array}$ & Sig. F change \\
\hline Model 1: Age & 0.770 & 0.593 & 0.588 & 3.451 & $<0.001$ \\
\hline Model 2: Age + APHV & 0.773 & 0.597 & 0.586 & 3.459 & 0.427 \\
\hline Model 3: Age + body mass & 0.779 & 0.607 & 0.591 & 3.439 & 0.170 \\
\hline Model 4: Age + LLL & 0.782 & 0.611 & 0.601 & 3.396 & 0.065 \\
\hline Model 5: Age + body fat & 0.771 & 0.594 & 0.583 & 3.471 & 0.740 \\
\hline
\end{tabular}

LLL: lower limb length.

TABLE 8 | Multiple regression analyses for composite COD scores.

\begin{tabular}{|c|c|c|c|c|c|}
\hline Model & $\mathbf{R}$ & R square & $\begin{array}{l}\text { Adjusted R } \\
\text { square }\end{array}$ & $\begin{array}{l}\text { SE of the } \\
\text { estimate }\end{array}$ & $\begin{array}{c}\text { Sig. } \\
\text { F change }\end{array}$ \\
\hline Model 1: Age & 0.732 & 0.535 & 0.529 & 2.094 & $<0.001$ \\
\hline Model 3: Age + APHV + LLL & 0.780 & 0.609 & 0.593 & 1.946 & 0.020 \\
\hline Model 4: Age + APHV + LLL + body fat & 0.784 & 0.615 & 0.594 & 1.945 & 0.299 \\
\hline
\end{tabular}

LLL: lower limb length.

TABLE 9 | Multiple regression analyses for composite strength scores.

\begin{tabular}{|c|c|c|c|c|c|}
\hline Model & $\mathbf{R}$ & R square & $\begin{array}{l}\text { Adjusted R } \\
\text { square }\end{array}$ & $\begin{array}{l}\text { SE of the } \\
\text { estimate }\end{array}$ & Sig. F change \\
\hline Model 1: Age & 0.799 & 0.639 & 0.633 & 8.508 & $<0.001$ \\
\hline Model 2: Age + APHV & 0.800 & 0.640 & 0.631 & 8.538 & 0.495 \\
\hline Model 3: Age + body mass & 0.800 & 0.641 & 0.626 & 8.591 & 0.811 \\
\hline Model 4: Age + LLL & 0.800 & 0.641 & 0.621 & 8.648 & 0.894 \\
\hline Model 5: Age + body fat. & 0.801 & 0.642 & 0.617 & 8.893 & 0.823 \\
\hline
\end{tabular}

LLL: lower limb length.

with respect to playing positions, and the literature contains data showing such effects in adult players. Wings undertake the greatest amounts of high-intensity running/sprinting, but are involved in fewer one-on-one duels than other players. Pivots cover less distance but are more involved in physical duels and contacts, while backs shoot and pass significantly more compared to the other playing positions (Milanese et al., 2011; Karcher and Buchheit, 2014). These differences lead to differences in anthropometric variables with playing position (Chaouachi et al., 2009; Vila et al., 2012). Chaouachi et al. (2009) demonstrated differences of heights between backs and wings, and in the percentage body fat between goalkeepers and backs in elite Tunisian national handball players. Others have reported that relative to other playing positions wings were significantly lighter and shorter, with less lean body mass and fat mass (Srhoj et al., 2002; Sibila and Pori, 2009; Sporis et al., 2010; Milanese et al., 2011). Sporis et al. (2010) examined a sample of ninetytwo elite Croatian handball players, finding that goalkeepers were the oldest, the wings were the shortest and the pivots were the tallest players in the team, while backcourt players had a low percentage of body fat. Ghobadi et al. (2013) also noted that line players (pivots) were the heaviest, backcourt and line players were the tallest, and goalkeepers were older than the center backcourt, backcourt and wing players $(p<0.05)$.

Haugen et al. (2016) quantified differences in both anthropometric and physical characteristics according to 
playing position and competitive level in elite male handball players. They showed that backs achieved higher throwing velocities than other positions, and wings sprinted faster and jumped higher than pivots and goalkeepers However, back players and wings had greater squat strength than pivots, while pivots were $9 \%$ stronger than wing players in 1RM bench press. Massuca et al. (2015) also found significant effects of playing position on body size and fitness performance. Back left/right players had an advantage in handgrip strength, and central back and pivot players also scored better on handgrip strength than goalkeeper and wing players.

\section{Practical Value of Data on Maturity Status and Anthropometric Characteristics}

Our univariate analyses suggest that age, maturity status and anthropometric characteristics all influence scores on performance-related physical tests. However, because a player's physical characteristics are closely related to age, multiple regression analyses using data that cover the adolescent age range attribute almost all of this variance to age alone. It remains to be demonstrated how far assessments of age, maturity and measurement of anthropometric characteristics can help in player selection, placement and training. In any sport, highly motivated individuals can succeed despite what seems a very unfavorable anthropometric profile, and trainers rely heavily on observing players during actual competition rather than on laboratory data. Nevertheless, these characteristics do seem to influence coaching decisions. Thus, Matthys et al. (2013) noted that youth players with the most advanced maturation status and the most favorable anthropometry and physical fitness scores were consistently positioned in the back position. In contrast, players with a less advanced maturity status and an overall smaller stature were placed on the wing or pivot positions.

\section{Strengths and Limitations of Study}

The main strength of this research is the collection of data on a substantial sample of handball players across age groups that previously have not received great attention. The findings that we report are relevant to the current university population in Tunisia, but we recognize that the rate of attainment of maximal growth differs in other cultures and environments, limiting the generality of our results. Other important limitations include the overwhelming impact of age in the multiple regression analyses, the inability to examine the influence of playing position, and the absence of data on female adolescents. Future observations should focus on a large sample within a single age category, and should include information on performance during actual handball games. Further, we did not assess local muscle mass; this could be a much more interesting variable than total body mass to consider in future investigations. Also, the older and more experienced players had the advantage of having attempted many of the performance tests on previous occasions, and despite familiarization sessions, this may have influenced the scores that they attained relative to the younger players. Other factors that merit consideration in future research include possible effects arising from an age-related displacement of the center of mass, and the development of player position-specific fatigue.

\section{CONCLUSION}

The present findings underline the progressive age-related development of factors influencing performance throughout adolescence, indicating the importance of age-categorized competition in handball until at least the age of 19 years. The data also showed moderate to very large univariate relationships between the performance realized by both upper and lower limb muscles and the anthropometric characteristics of male handball players, particularly body mass, height and lower limb length. Future studies should focus on narrower age ranges, and should examine the impact of other anthropometric characteristics, such as chest circumference and the length and volume of the upper limbs.

\section{ETHICS STATEMENT}

This study was reviewed and approved by the Institute's Committee on Research for the Medical Sciences (Manouba University Ethics Committee) and performed in accordance with the current national laws and regulations and the Declaration of Helsinki. Informed consent was gained from all participants and their parents or guardians after a verbal and a written explanation of the experimental protocol and its potential risks and benefits. Participants were assured that they could withdraw from the trial without penalty at any time.

\section{AUTHOR CONTRIBUTIONS}

$\mathrm{MC}, \mathrm{MH}, \mathrm{PC}, \mathrm{SH}$, and RS carried out the formal analysis and supervised the study. HM, NG, and GA investigated the study. HM, NG, and SH developed the methodology. MC and $\mathrm{HM}$ administered the project. $\mathrm{MH}, \mathrm{NG}, \mathrm{SH}$, and $\mathrm{MC}$ drafted the manuscript. $\mathrm{SH}, \mathrm{MH}, \mathrm{MC}$, and $\mathrm{RS}$ reviewed and edited the manuscript.

\section{ACKNOWLEDGMENTS}

The authors thank the "Ministry of Higher Education and Scientific Research, Tunis, Tunisia" for the financial support. The authors also thank Associate Professor Ridha Aouedi, Ph.D. [Research Unit (UR17JS01) "Sport Performance, Health and Society," Higher Institute of Sport and Physical Education of Ksar Saïd, University of "La Manouba", Tunis, Tunisia] for the valuable statistical help. The publication of this article was funded by the Qatar National Library. 


\section{REFERENCES}

Aouadi, R., Jlid, M. C., Khalifa, R., Hermassi, S., Chelly, M. S., Van Den Tillaar, R., et al. (2012). Association of anthropometric qualities with vertical jump performance in elite male volleyball players. J. Sports Med. Phys. Fit. 52, 11-17.

Barnsley, R. H., and Thompson, A. H. (1988). Birthdate and success in minor hockey: the key to the NHL. Can. J. Beh. Sci. 167-176. doi: 10.1037/h0079927

Baxter-Jones, A. D. (1995). Growth and development of young athletes. Should competition levels be age related? Sports Med. 20, 59-64. doi: 10.2165/ 00007256-199520020-00001

Chamari, K., Chaouachi, A., Hambli, M., Kaouech, F., Wisloff, U., and Castagna, C. (2008). The five-jump test for distance as a field test to assess lower limb explosive power in soccer players. J. Strength Cond. Res. 22, 944-950. doi: 10.1519/JSC.0b013e31816a57c6

Chaouachi, A., Brughelli, M., Levin, G., Boudhina, N. B., Cronin, J., and Chamari, K. (2009). Anthropometric, physiological and performance characteristics of elite team-handball players. J. Sports Sci. 27, 151-157. doi: 10.1080/ 02640410802448731

Chelly, M. S., Hermassi, S., and Shephard, R. J. (2010). Relationships between power and strength of the upper and lower limb muscles and throwing velocity in male handball players. J. Strength Cond. Res. 24, 1480-1487. doi: 10.1519/JSC. 0b013e3181d32fbf

Delorme, N., Chalabaev, A., and Raspaud, M. (2011). Relative age is associated with sport dropout: evidence from youth categories of French basketball. Scand J. Med. Sci. Sports 21, 120-128. doi: 10.1111/j.1600-0838.2009. 01060.x

Durnin, J. V., and Womersley, J. (1974). Body fat assessed from total body density and its estimation from skinfold thickness: measurements on 481 men and women aged from 16 to 72 years. Br. J. Nutr. 32, 77-97. doi: 10.1079/ bjn 19740060

International Handball Federation (2014). Available at: http://archive.ihf.info/enus/ihfcompetitions/competitionsarchive.aspx

Fernández, J. J., Vila, M. J., and Rodriguez, F. A. (2004). Modelo de un estudio de la estructura condicional a través de un análisis multivariante enfocado a la detección de talentos en jugadores de balonmano. Mot. Eur. J. Hum. Mov. 2004, 169-185.

Fowkes Godek, S., Godek, J. J., and Bartolozzi, A. R. (2004). Thermal responses in football and cross-country athletes during their respective practices in a hot environment. J. Athl. Train 39, 235-240.

Ghobadi, H., Rajabi, H., Farzad, B., Bayati, M., and Jeffreys, I. (2013). Anthropometry of world-class elite handball players according to the playing position: reports from men's handball world championship 2013. J. Hum. Kinet 39, 213-220. doi: 10.2478/hukin-2013-0084

Gillespie, J., and Keenum, S. (1987). A validity and reliability analysis of the seated shot put as a test of power. J. Human. Mov. Stud. 13, 97-105. doi: 10.1519/JSC. 0b013e3181e7259c

Gómez-López, M., Angosto, S., and Ruiz-Sánchez, V. (2017). Relative age effect in the selection process of handball players of the regional selection teams. E-Balonmanocom. J. Sport Sci 13, 3-14.

Granados, C., Izquierdo, M., Ibanez, J., Bonnabau, H., and Gorostiaga, E. M. (2007). Differences in physical fitness and throwing velocity among elite and amateur female handball players. Int. J. Sports Med. 28, 860-867. doi: 10.1055/ s-2007-964989

Gutierrez Diaz Del Campo, D., Pastor Vicedo, J. C., Gonzalez Villora, S., and Contreras Jordan, O. R. (2010). The relative age effect in youth soccer players from Spain. J. Sports Sci. Med. 9, 190-198.

Hachana, Y., Chaabene, H., Ben Rajeb, G., Khlifa, R., Aouadi, R., Chamari, K., et al. (2014). Validity and reliability of new agility test among elite and subelite under 14-soccer players. PLoS One 9:e95773. doi: 10.1371/journal.pone.009 5773

Hannibal, N. S., Plowman, S. A., Looney, M. A., and Brandenburg, J. (2006). Reliability and validity of low back strength/muscular endurance field tests in adolescents. J. Phys. Act. Health 3, S78-S89.

Haugen, T. A., Tonnessen, E., and Seiler, S. (2016). Physical and physiological characteristics of male handball players: influence of playing position and competitive level. J. Sports Med. Phys. Fit. 56, 19-26.
Helsen, W. F., Starkes, J. L., and Van Winckel, J. (1998). The influence of relative age on success and dropout in male soccer players. Am. J. Hum. Biol. 10, 791-798. doi: 10.1002/(SICI)1520-6300199810:6

Helsen, W. F., Van Winckel, J., and Williams, A. M. (2005). The relative age effect in youth soccer across Europe. J. Sports Sci. 23, 629-636. doi: 10.1080/ 02640410400021310

Hermassi, S., Chelly, M. S., Fieseler, G., Bartels, T., Schulze, S., Delank, K. S., et al. (2017a). Effects of In-season explosive strength training on maximal leg strength, jumping, sprinting, and intermittent aerobic performance in male handball athletes. Sportverletz. Sportschaden 31, 167-173. doi: 10.1055/s-0043103469

Hermassi, S., Chelly, M. S., Wollny, R., Hoffmeyer, B., Fieseler, G., Schulze, S., et al. (2018a). Relationships between the handball-specific complex test, non-specific field tests and the match performance score in elite professional handball players. J. Sports Med. Phys. Fitness 58, 778-784. doi: 10.23736/S0022-4707.17. 07373-X

Hermassi, S., Schwesig, R., Wollny, R., Fieseler, G., van den Tillaar, R., FernandezFernandez, J., et al. (2018b). Shuttle versus straight repeated-sprint ability tests and their relationship to anthropometrics and explosive muscular performance in elite handball players. J. Sports Med. Phys. Fitness 58, 1625-1634. doi: 10. 23736/S0022-4707.17.07551-X

Hermassi, S., Wollny, R., Schwesig, R., Shephard, R. J., and Chelly, M. S. (2017b). Effects of in-season circuit training on physical abilities in male handball players. J. Strength Cond. Res. 7, 944-957. doi: 10.1519/JSC.0000000000002270

Karcher, C., and Buchheit, M. (2014). On-court demands of elite handball, with special reference to playing positions. Sports Med. 44, 797-814. doi: 10.1007/ s40279-014-0164-z

Kruger, K., Pilat, C., Uckert, K., Frech, T., and Mooren, F. C. (2014). Physical performance profile of handball players is related to playing position and playing class. J. Strength Cond. Res. 28, 117-125. doi: 10.1519/JSC. 0b013e318291b713

Lidor, R., Falk, B., Arnon, M., Cohen, Y., Segal, G., and Lander, Y. (2005). Measurement of talent in team handball: the questionable use of motor and physical tests. J. Strength Cond. Res. 19, 318-325. doi: 10.1519/00124278200505000-00014

Lucia, A., Hoyos, J., Perez, M., Santalla, A., and Chicharro, J. L. (2002). Inverse relationship between VO2max and economy/efficiency in world-class cyclists. Med. Sci. Sports Exerc. 34, 2079-2084. doi: 10.1097/00005768-20021200000032

Massuca, L., Branco, B., Miarka, B., and Fragoso, I. (2015). Physical fitness attributes of team-handball players are related to playing position and performance level. Asian J. Sports Med. 6, e24712. doi: 10.5812/asjsm.24712

Matthys, S. P., Fransen, J., Vaeyens, R., Lenoir, M., and Philippaerts, R. (2013). Differences in biological maturation, anthropometry and physical performance between playing positions in youth team handball. J. Sports Sci. 31, 1344-1352. doi: 10.1080/02640414.2013.781663

Meylan, C., and Malatesta, D. (2009). Effects of in-season plyometric training within soccer practice on explosive actions of young players. J. Strength Cond. Res. 23, 2605-2613. doi: 10.1519/JSC.0b013e3181b1f330

Michalsik, L. B., Aagaard, P., and Madsen, K. (2013). Locomotion characteristics and match-induced impairments in physical performance in male elite team handball players. Int. J. Sports Med. 34, 590-599. doi: 10.1055/s-0032-1329989

Michalsik, L. B., Madsen, K., and Aagaard, P. (2015). Technical match characteristics and influence of body anthropometry on playing performance in male elite team handball. J. Strength Cond. Res. 29, 416-428. doi: 10.1519/ JSC.0000000000000595

Milanese, C., Piscitelli, F., Lampis, C., and Zancanaro, C. (2011). Anthropometry and body composition of female handball players according to competitive level or the playing position. J. Sports Sci. 29, 1301-1309. doi: 10.1080/02640414. 2011.591419

Mirwald, R. L., Baxter-Jones, A. D., Bailey, D. A., and Beunen, G. P. (2002). An assessment of maturity from anthropometric measurements. Med. Sci. Sports Exerc. 34, 689-694. doi: 10.1249/00005768-200204000-00020

Mohamed, H., Vaeyens, R., Matthys, S., Multael, M., Lefevre, J., Lenoir, M., et al. (2009). Anthropometric and performance measures for the development of a talent detection and identification model in youth handball. J. Sports Sci. 27, 257-266. doi: 10.1080/02640410802482417 
Musch, J., and Grondin, S. (2001). Unequal competition as an impediment to personal development: a review of the relative age effect in sport. Dev. Rev. 21, 147-167. doi: 10.1006/drev.2000.0516

Nag, A., Nag, P. K., and Desai, H. (2003). Hand anthropometry of indian women. Indian J. Med. Res. 117, 260-269.

Ortega-Becerra, M., Pareja-Blanco, F., Jimenez-Reyes, P., Cuadrado-Penafiel, V., and Gonzalez-Badillo, J. J. (2018). Determinant factors of physical performance and specific throwing in handball players of different ages. J. Strength Cond. Res. 32, 1778-1786. doi: 10.1519/JSC.0000000000002050

Pearson, D. T., Naughton, G. A., and Torode, M. (2006). Predictability of physiological testing and the role of maturation in talent identification for adolescent team sports. J. Sci. Med. Sport 9, 277-287. doi: 10.1016/j.jsams.2006. 05.020

Prieto-Ayuso, A., Pastor-Vicedo, J. C., Serra-Olivares, J., and González-Víllora, S. (2015). Relative age effect in spanish football: the 2013/14 season. Apunts Phys. Educ. Sports 121, 36-43.

Roemmich, J. N., and Rogol, A. D. (1995). Physiology of growth and development. Its relationship to performance in the young athlete. Clin. Sports Med. 14, 483-502.

Salinero, J. J., Pérez, B., Burillo, P., Lesma, M. L., and Herrero, M. H. (2014). Relative age effect in professional spanish football. Rev. Int. Med. Cienc. Act.Fís.Deporte. 14, 591-601.

Sassi, R. H., Dardouri, W., Yahmed, M. H., Gmada, N., Mahfoudhi, M. E., and Gharbi, Z. (2009). Relative and absolute reliability of a modified agility T-test and its relationship with vertical jump and straight sprint. J. Strength Cond. Res. 23, 1644-1651. doi: 10.1519/JSC.0b013e3181b425d2

Schorer, J., Cobley, S., Busch, D., Brautigam, H., and Baker, J. (2009). Influences of competition level, gender, player nationality, career stage and playing position on relative age effects. Scand. J. Med. Sci. Sports 19, 720-730. doi: 10.1111/j. 1600-0838.2008.00838.x

Schwesig, R., Hermassi, S., Fieseler, G., Irlenbusch, L., Noack, F., Delank, K. S., et al. (2017). Anthropometric and physical performance characteristics of professional handball players: influence of playing position. J. Sports Med. Phys. Fit. 57, 1471-1478. doi: 10.23736/S0022-4707.16.06413-6

Schwesig, R., Hermassi, S., Hoffmeyer, B., Irlenbusch, L., Fieseler, G., Noack, F., et al. (2016). Relationship between the handball-specific complex-test and intermittent field test performance in elite professional handball players. J. Sports Med. Phys. Fitness.

Sherar, L. B., Baxter-Jones, A. D., Faulkner, R. A., and Russell, K. W. (2007). Do physical maturity and birth date predict talent in male youth ice hockey players? J. Sports Sci. 25, 879-886. doi: 10.1080/02640410600908001

Sibila, M., and Pori, P. (2009). Position-related differences in selected morphological body characteristics of top-level handball players. Coll. Antropol. 33, 1079-1086.

Sporis, G., Vuleta, D., Vuleta, D. Jr., and Milanovic, D. (2010). Fitness profiling in handball: physical and physiological characteristics of elite players. Coll. Antropol. 34, 1009-1014.

Srhoj, V., Marinovic, M., and Rogulj, N. (2002). Position specific morphological characteristics of top-level male handball players. Coll. Antropol. 26, 219-227.
Tanner, J. M. (1962). Growth at Adolescence. Hoboken: Blackwell Scientific Publication.

Van Praagh, E., and Dore, E. (2002). Short-term muscle power during growth and maturation. Sports Med. 32, 701-728. doi: 10.2165/00007256-20023211000003

Vila, H., Manchado, C., Rodriguez, N., Abraldes, J. A., Alcaraz, P. E., and Ferragut, C. (2012). Anthropometric profile, vertical jump, and throwing velocity in elite female handball players by playing positions. J. Strength Cond. Res. 26, 2146-2155. doi: 10.1519/JSC.0b013e31823b0a46

Vincent, W. (1995). Statistics in Kinesiology. Champaign, IL: Human Kinetics.

Vint, P. F., and Hinrichs, R. N. (1996). Differences between one foot and two-foot vertical jump performances. J. App. Biomech. 12, 338-358. doi: 10.1123/jab.12. 3.338

Visnapuu, M., and Jurimae, T. (2007). Handgrip strength and hand dimensions in young handball and basketball players. J. Strength Cond. Res. 21, 923-929. doi: 10.1519/00124278-200708000-00045

Wagner, H., Finkenzeller, T., Wurth, S., and Von Duvillard, S. P. (2014). Individual and team performance in team-handball: a review. J. Sports Sci. Med. 13, 808-816.

Wagner, H., Fuchs, P. X., and Von Duvillard, S. P. (2018). Specific physiological and biomechanical performance in elite, sub-elite and in non-elite male team handball players. J. Sports Med. Phys. Fit. 58, 73-81. doi: 10.23736/S0022-4707. 16.06758-X

Wagner, H., Gierlinger, M., Adzamija, N., Ajayi, S., Bacharach, D. W., and Von Duvillard, S. P. (2017). Specific physical training in elite male team handball. J. Strength Cond. Res. 31, 3083-3093. doi: 10.1519/JSC.00000000000 02094

Wagner, H., Sperl, B., Bell, J. W., and Von Duvillard, S. P. (2019). Testing specific physical performance in male team handball players and the relationship to general tests in team sports. J. Strength Cond. Res. 33, 1056-1064. doi: 10.1519/ JSC.0000000000003026

Ziv, G., and Lidor, R. (2009). Physical characteristics, physiological attributes, and on-court performances of handball players: a review. Eur. J. Sport Sci. 9, 375-386. doi: 10.1519/JSC.0b013e3182891535

Conflict of Interest Statement: The authors declare that the research was conducted in the absence of any commercial or financial relationships that could be construed as a potential conflict of interest.

The reviewer HW declared a past co-authorship with one of the authors SH to the handling Editor.

Copyright (c) 2019 Hammami, Hermassi, Gaamouri, Aloui, Comfort, Shephard and Chelly. This is an open-access article distributed under the terms of the Creative Commons Attribution License (CC BY). The use, distribution or reproduction in other forums is permitted, provided the original author(s) and the copyright owner(s) are credited and that the original publication in this journal is cited, in accordance with accepted academic practice. No use, distribution or reproduction is permitted which does not comply with these terms. 